Bioactive Properties of the Aqueous Extracts of Endophytic Fungi Associated with Scots Pine (Pinus sylvestris) Roots

\title{
Tienaho, Jenni
}

2020-09

Tienaho , J , Karonen, M , Muilu-Mäkelä , R , Kaseva , J , de Pedro , N , Vicente , F , Genilloud, O , Aapola , U , Uusitalo , H, Vuolteenaho , K, Franzen , R , Wähälä , K, Karp , M , Santala , V \& Sarjala , T 2020 , ' Bioactive Properties of the Aqueous Extracts of Endophytic Fungi Associated with Scots Pine (Pinus sylvestris) Roots ' , Planta Medica, vol. 86 , no. 13/14 , pp. 1009-1024 . https://doi.org/10.1055/a-1185-4437

http://hdl.handle.net/10138/330790

https://doi.org/10.1055/a-1185-4437

unspecified

acceptedVersion

Downloaded from Helda, University of Helsinki institutional repository.

This is an electronic reprint of the original article.

This reprint may differ from the original in pagination and typographic detail.

Please cite the original version. 


\section{Bioactive Properties of the Aqueous Extracts of Endophytic Fungi Associated}

\section{with Scots Pine (Pinus sylvestris) Roots}

Jenni Tienaho ${ }^{1,2, *}$, Maarit Karonen ${ }^{3}$, Riina Muilu-Mäkelä ${ }^{2}$, Janne Kaseva ${ }^{4}$, Nuria de Pedro ${ }^{5}$, Francisca

Vicente $^{5}$, Olga Genilloud ${ }^{5}$, Ulla Aapola ${ }^{6}$, Hannu Uusitalo ${ }^{6,7}$, Katriina Vuolteenaho ${ }^{8}$, Robert Franzén ${ }^{9}$, Kristiina Wähälä ${ }^{10,11}$, Matti Karp ${ }^{1}$, Ville Santala ${ }^{1}$, Tytti Sarjala ${ }^{2}$

\section{Affiliation}

${ }^{1}$ Faculty of Natural Sciences and Engineering, Tampere University, Tampere, Finland

${ }^{2}$ Natural Resources Institute Finland (Luke), Production Systems Unit, Biomass Characterization and Properties Group, Finland

${ }^{3}$ Natural Chemistry Research Group, Department of Chemistry, University of Turku, Turku, Finland

${ }^{4}$ Natural Resources Institute Finland (Luke), Natural Resources Unit, Applied Statistical Methods Group, Finland

${ }^{5}$ Fundación MEDINA, Avda. del Conocimiento, Granada, Spain

${ }^{6}$ Department of Ophthalmology, Faculty of Medicine and Health Technology, Tampere University, Tampere, Finland

${ }^{7}$ Tays Eye Centre, Tampere University Hospital, Tampere, Finland

${ }^{8}$ The Immunopharmacology Research Group, Faculty of Medicine and Health Technology, Tampere University and Tampere University Hospital, Tampere, Finland

${ }^{9}$ School of Chemical Engineering, Department of Chemistry and Materials Science, Aalto University, Espoo, Finland

${ }^{10}$ Department of Biochemistry and Developmental Biology, University of Helsinki, Finland

${ }^{11}$ Department of Chemistry, University of Helsinki, Helsinki, Finland

${ }^{*}$ Corresponding author

\section{Correspondence}

D. Sc. (Tech.) Jenni Tienaho, Tampere University, Korkeakoulunkatu 8, FI-33101 Tampere, Finland and Natural Resources Institute Finland, Maarintie, FI-02150 Espoo, Finland, jenni.tienaho@tuni.fi; ext.jenni.tienaho@luke.fi; Phone: +358-29-532-4986 


\begin{abstract}
Despite the continuing interest in various plant and natural products, only a small portion of the biologically active compounds from nature has been discovered and exploited. In this study, antioxidant and antibacterial properties of aqueous fractions of three endophytic fungi isolated from the roots of eight-yearold Scots pines (Pinus sylvestris) growing on a drained peatland were investigated. The endophytic fungi species were Acephala applanata, Phialocephala fortinii and Humicolopsis cephalosporioides / Coniochaeta mutabilis. The bioactivities were examined using hydrogen peroxide scavenging (SCAV) and oxygen radical absorbance capacity (ORAC) tests as well as sensitive Escherichia coli-based biosensors, which produce a luminescent signal in the presence of substances with oxidative or genotoxic properties. In addition, cell models for Parkinson's disease (PD), age-related macular degeneration (AMD) and osteoarthritis (OA) were used to evaluate the potential for pharmaceutical applications. The aqueous extracts of fungi and 19 out of 42 fractions were found active in one or more of the tests used. However, no activity was found in the AMD and OA cell model tests. Additionally, bioactivity data was connected with metabolites putatively annotated, and out of 330 metabolites, 177 were interesting in view of the bioactivities investigated. A majority of these were peptides and all three fungal species shared a highly similar metabolome. We propose that Scots pine endophytic fungi are a rich source of interesting metabolites and synergistic effects may cause the bioactivities, as they were found to vary after the fractionation process.
\end{abstract}

\title{
Keywords
}

Acephala applanata, antibacterial, antioxidant, Coniochaeta mutabilis, endophytic fungi, Humicolopsis cephalosporioides, Leotimycetidae, Phialocephala fortinii, Sordariomycetidae 


\section{Introduction}

Endophyte, from Greek 'endon', meaning within, and 'phyton', meaning a plant, is a term literally referring to an organism living inside a plant host. The most common endophytes are fungi or bacteria and the term usually refers to these microbial species. Endophytic infections are inconspicuous, and the endophyte lives asymptomatically inside the plant host for at least some part of its lifecycle [1]. The endophytes receive nutrition and protection from the host, and they return the favor by enhancing the survival and fitness of the host plant by producing functional metabolites with various biological activities including antimicrobial, antiviral, insecticidal and antioxidant properties [2-4]. The growth habitat and environmental conditions of the host plant affect the diversity and amount of the endophytic populations and unique or extreme growth conditions may yield novel endophytic lead compounds with bioactive or even medicinal properties [4].

Drained peatlands express alternating drought and temperature levels and therefore create abiotic stress conditions for the growth and survival of Scots pine (Pinus sylvestris L., Pinaceae) seedlings. Dark septate endophytic (DSE) fungi are common in the roots of Scots pine and have been reported to contribute to the stress tolerance and the increased growth of the host [5]. We have previously described the metabolites in the aqueous extracts of three DSE fungi, Acephala applanata (Leotimycetidae), Phialocephala fortinii (Leotimycetidae) and Humicolopsis cephalosporioides (Sordariomycetidae)/Coniochaeta mutabilis (Sordariomycetidae) (The collection of Natural Resources Institute Finland) isolated from the Scots pine roots growing on drained peatlands. Out of 318 metabolites from three fungus extracts, 220 were putatively annotated [6]. While there are numerous studies focusing on the endophytic fungi extraction with organic solvents, little is known about the water-extractable metabolites obtained from endophytic fungi and their bioactivities. Aqueous extracts have also yielded important bioactive principles from the caterpillar parasitic fungus Cordyceps sinensis [7]. The minimal environmental impact, renewability and solvent recycling issues make aqueous extraction an interesting alternative for organic solvent extraction. 
Oxidative stress is a common factor in the development of many severe diseases. Age-related macular degeneration (AMD) is a major cause of vision impairment in elderly people worldwide. It is characterized by the progressive loss of vision due to degenerative and neovascular changes in the central region of the retina, the macula [8]. Chronic oxidative stress and inflammation are strongly linked to AMD pathogenesis. Oxidative stress has also been linked with osteoarthritis (OA), which is a slowly progressing inflammatory disease causing pain and stiffness in the joints, as reactive oxygen species (ROS) cause cartilage degradation in experimental arthritis [9]. OA is the most common cause of musculoskeletal disability and pain. However, current therapy for OA is symptomatic and no treatment is available to prevent or retard the disease progression [9]. Additionally, oxidative stress and aging play a major role in the neuron degeneration by the Parkinson's disease (PD), leading to mitochondrial dysfunction and even cell death [10]. Given the severity and socio-economic impact of these widely spread diseases, there is an enormous need for the development of new therapeutics for these oxidative stress related diseases.

In this study, the antioxidant and antibacterial properties of the fungal extracts and fractions obtained using preparative liquid chromatography were examined. Stress-responsive luminescent bacterial biosensors were used, which are sensitive towards substances inducing oxidative stress (Escherichia coli DPD2511) [11] or DNA damage (E. coli DPD2794) [12]. Biosensors give valuable insights to the mechanism of action behind antibacterial effects as they react specifically to distinct types of the stress conditions through the genetic engineering of regulatory elements guiding the expression of reporter genes. The oxidative stress responsive E. coli DPD2511 sensor was also used to detect antioxidant activity using the method described by Tienaho et al. [13]. In addition, the antioxidant nature of the fractions was examined using hydrogen peroxide scavenging (SCAV) assay [14] and oxygen radical absorbance capacity with fluorescent probe (ORAC-FL) microplate methods [15]. Antioxidants function via multiple mechanisms and the tests used measure their different aspects. In order to assess the pharmacological potential of the extracts, they were examined using three human cell model tests: AMD [16-17], OA [18] and PD [19]. Finally, the bioactive properties of the active or inactive fractions of the extracts were 
examined together with the data of the metabolite composition of the fractions. These were obtained in our earlier study [6] using high-resolution LC-MS.

\section{Results and Discussion}

In this study, the focus is on the analysis of the antioxidant and antibacterial properties of endophytic fungal extracts and fractions. Additionally, three human cell models (AMD, OA and PD) were used for the assessment of pharmacological potential. The data obtained is then connected with the information about the metabolites putatively annotated. The metabolic profile of the fungal extracts A. applanata (cultivation code A), P. fortinii (R) and H. cephalosporioides or C. mutabilis (S16) was described in an earlier study [6]. For simplicity, the cultivation codes A, R and S16 of the extracts are used. Before bioactivity testing, the aqueous fungal extracts were fractionated by preparative high-performance liquid chromatography (HPLC) to 13, 15 and 14 fractions for A, R and S16, respectively. The fractionation yields were 0.1-19.1 mg /fraction (dry weight). The metabolites in the bioactive fractions were subsequently putatively annotated.

The antioxidant and antibacterial as well as cell line test activities of the extracts and fractions are shown in Table 1. Apart from the cell model tests, which were not conducted for fractions, the extracts were active in most of the tests and the fractions did not have the same activities. In general, if one or more fractions of the extract were active, the extract was also active. However, this was not true for oxidative stress biosensor and ORAC tests. In the ORAC test, the extracts were active, even when fractions were not. This suggests that the synergism of metabolites causes the activities in the extracts and it can be lost in the fractionation process. Changes during the fractionation or the drying process of fractions as well as the concentration differences can also affect the bioactivities.

The luminescent E. coli biosensors have been previously used to screen natural substances. For example, the E. coli DPD2794 sensor has been used to screen the antibacterial activity of herbal tinctures [20], while the E. coli DPD2511 sensor has been used to screen the antioxidant properties of medicinal plants from the Philippines [21]. Tienaho et al. [13] introduced a microplate method and used the same 
sensor to screen for the antioxidant properties of Norway spruce (Picea abies [L.] Karst) bark extracts. These biosensor methodologies are sensitive enough to detect even the low concentrations of active substances, which is necessary in the case of fractionated samples. In the bacterial biosensor tests, the fractions were considered active if the induction factors (luminescence induction compared with water blank) rose above one (IF > 1) in a dose responsive manner as in Fig. 1. The maximum IF values of the active fractions with the oxidative stress sensor were between 1.2 and 4.5 and with DNA damage sensor 1.2 and 5.5. The antioxidant fractions produced maximal \%-inhibition values between 2.0 and $40.0 \%$ within 3 to 9 time points when the signal was lower than that of hydrogen peroxide. In the case of antioxidant activities, the first $10 \mathrm{~min}$ was needed for the temperature to stabilize and the rise in \%-inhibition was considered showing activity when it occurred during 10 to 50 minutes of the measurement.

The SCAV test measures the ability of an antioxidant to scavenge hydrogen peroxide before it oxidizes iron according to a Fenton-type reaction, which produces hydroxyl radicals [22]. The fractions active in the SCAV test gave values between 0.62 to $2.1 \mathrm{mg} / \mathrm{mL}$ of sodium pyruvate equivalents. These correspond to approximately $1-10 \%$-inhibition of $\mathrm{H}_{2} \mathrm{O}_{2}$. The ORAC assay measures the oxidative dissociation of the fluorescein molecule in the presence of peroxyl radicals (ROO•), which causes a reduction in the fluorescence signal. The antioxidant activity is therefore measured by the activity to inhibit the peroxyl radical from interfering with the fluorescent molecules. The ORAC test of the fractions gave values from under 10 to over 2000 Trolox equivalent (TE) $\mu \mathrm{mol} / \mathrm{L}$ and here the values over 500 were considered active (Table 1).

Cell model tests were conducted for the extracts alone and no activity was detected in the case of AMD or OA. However, the extract A showed activity in the PD cell model test (maximum inhibition activity -\% 40). This means that even though antioxidant activity could be detected with several test methods, the extracts were not active in all the cell model tests related to oxidative stress. An intracellular penetration of compounds or both synergistic and antagonistic effects between the cells and extracts or between separate compounds inside the extracts could explain these findings. 
The metabolic profiling process and all the putatively anmotated and unidentified metabolites from the fungal extracts have been described earlier [6]. The information about the characterization of the metabolites by high-resolution mass spectrometry containing, for example, the structural information with measured exact masses and in-source fragment ions, retention times, and the standards used, are also shown in Tienaho et al. [6]. All metabolites discovered from the extracts and fractions are shown in Table 1S, while Table 2 shows the metabolites that have been only found in the active or only in the inactive fractions and extracts. In other words, if a metabolite was found both in the bioactivity test active and inactive fractions or extracts, it was omitted. From the initial 330 compounds, 177 (54\%) are shown in the Table. The metabolites in bold were tested separately using SCAV and ORAC tests and these results are shown in Table 3.

Most of the metabolites putatively annotated in the bioactive fractions were peptides with a tentative identification of 83 dipeptides or short peptides and 9 derivatives such as acetylamino or phenylacetylamino acids. This group represents 52\% of the 177 metabolites. Additionally, 51 unidentified compounds, representing $29 \%$ of the metabolites, influence the bioactivity of the fungal fractions. Other compounds such as nucleosides and nucleotides, Amadori compounds and sugars were also found among the compounds of potential bioactive interest, representing $19 \%$ of the metabolites. As found in our previous study [6], the fungal species have surprisingly similar metabolomes. A and $\mathrm{R}$ fungi belong to the Phialocephala fortinii - Acephala applanata complex (PAC), which are usually common root endophytes in the boreal trees whereas S16 is Humicolopsis cephalosporioides or Coniochaeta mutabilis, which have been found in plants but also act as human and animal pathogens. All three fungal strains were isolated at the same time and from the same ecological niche and host and from visually healthy pine seedling roots. In our previous study, we showed that over $60 \%$ of the metabolites putatively annotated were found in all the fungal species [6]. The small differences in the metabolome could indicate that the metabolite production variance is limited when using a sterile mycelium under a steady nutrient supply. Further evidence about the similarity of the metabolomes is found with clustering. The fractions F2-F4 (the first principal component (PC1) and PC3), F5-F7 (PC6) and F13-F15 (PC4 and PC5) from each fungus were 
linked together according to their metabolites based on cluster analysis (Table 2SA). This finding is logical and likely caused by the elution order of the similar molecules obtained from the fractions.

Authentic standard compounds of some of the identifications were tested for their antioxidant properties using SCAV and ORAC methods with $2 \mathrm{mg} / \mathrm{mL}$ concentration (Table 3). These included AlaGln, tyrosine, uridine, Ala-Tyr, Leu-Ala, Pro-Leu, Ala-Phe, Gly-Phe, Ala-Trp, Asp-Phe and Leu-Leu. Tryptophan, tyrosine, and dipeptides containing either of them showed bioactivities with these methods. The peptides containing Tyr or Trp were also found in the fractions showing antioxidant activity (SCAV ${ }^{\text {act }}$, ORAC $^{\text {act }}$, antiox ${ }^{\text {act }}$ ) (Table 2). Additionally, Ala-Gln and Ala-Phe were active in the SCAV test as individual compounds but in Table 2, they were found in $\mathrm{ox}^{\text {act }}$ and antiox ${ }^{\text {act }}$ fractions, respectively. This could be caused by a difference between the amount of the metabolite found in the fractions and the concentration of an authentic standard. Furthermore, the absence of interfering metabolites or the ability of some antioxidant peptides to act as pro-oxidants under certain conditions could explain the differences [23]. In Table 3, if a SCAV test gave values above 3\% $\mathrm{H}_{2} \mathrm{O}_{2}$ inhibition and ORAC above $500 \mathrm{TE} \mu \mathrm{mol} / \mathrm{L}$, the compound was considered as an active antioxidant.

In Fig. 2, the numbers of metabolites from active and inactive fractions and extracts in different bioactivity tests are shown in a Venn diagram form, visualizing and gathering the results of Table 2. Compound groups are presented as $\mathrm{P}=$ peptide, $\mathrm{O}=$ other and $\mathrm{U}=$ unknown. Detailed information about the compounds can be found in Table 2.

The free amino acid tyrosine (Tyr) was found in SCAV active fractions and extracts (Table 2). Tyrosine has been previously found to have antioxidant activity in the ORAC assay and this activity could be explained by the capacity of the phenolic groups to serve as proton donors [24]. The oxygen radical captures a phenolic hydrogen resulting in the formation of a more stable phenoxyl radical. In fact, nucleophilic sulfur-containing side chains (Cys and Met) and aromatic side chains (Trp, Tyr and Phe) are potential antioxidants but all can also have pro-oxidative properties under certain conditions [23]. Additionally, histidine (His) is susceptible to oxidative reactions due to its imidazole group, which also has metal chelating properties [23]. Especially acidic (Asp, Glu) but also basic (Arg, His, Lys) amino acid 
residues have been proposed to play an important role in metal chelation, thus, protecting from lipid peroxidation [25]. In addition, hydrophobic amino acids (Val, Leu and Ile) at the $\mathrm{N}$ terminus of peptides show antioxidant properties by increasing the interaction between peptides and fatty acids [26]. Interestingly, tryptophan was found to be active in SCAV and ORAC tests as an authentic standard compound, but it was found in both active and inactive fractions (Table 1S). Peptides containing the antioxidant Trp, Tyr, Phe, Cys, Met, Asp, Glu, Val, Leu, Ile, Arg, Lys or His amino acids were commonly found in $\mathrm{SCAV}^{\text {act }}, \mathrm{ORAC}^{\text {act }}, \mathrm{DNA}^{\text {act }}$ and/or antiox ${ }^{\text {act }}$ fractions (Table 2). In Table 2, only three tentative matches for peptides containing antioxidant counterparts were found in fractions with oxidative activities. The metabolite entry \#14 (Ala-Glu or Glu-Ala or heliopine) was found in ox $^{\text {act }}$ fractions; \#42 (di/tripeptide ${ }^{\text {h: }}$ potentially contains Leu, Ile, Val or Lys but possibly also the ethyl ester of Ala-Ala-Ala) was found in ox ${ }^{\text {act }}$, antiox $^{\text {inact }}$ and DNA ${ }^{\text {inact }}$ fractions and \#59 (acetylglutamic acid) was found in ox ${ }^{\text {act }}$ fractions. These identifications are however tentative, and thus could possibly be explained by other compound matches.

The high number of peptides putatively amnotated was also seen in the bioactive fractions. For example, most of the compounds found in SCAV and ORAC active fractions were different peptides and peptide derivatives (Fig. 2A and 2C). In addition, peptides also form the majority of the metabolites in the fractions active in the antiox and DNA biosensor tests (Fig. 2B and 2C). Furthermore, many of the metabolites found only in the PD active fractions are peptides: two out of five metabolites found only in the PD and SCAV active fractions and all three of the metabolites found only in PD and ORAC active fractions (Fig. 2A). Antioxidant peptides have been previously reported [24, 27]. Endophytes also use antioxidant substances to overcome the production of the reactive oxygen species (ROS), which is the initial protection behavior of the plant against microbial invasion [28]. For example, glutathione is an antioxidant peptide, known to be present at high concentrations in fungi [29]. Many peptides have also been reported showing antibacterial, antifungal and antiviral properties [27, 30-32].

Out of other compounds of interest, adenosine is adenine riboside, which has been shown to induce growth in plant meristem cultures [33-34]. Additionally, cytokinins are adenine derivative plant hormones, which are known to induce plant growth [35]. Adenosine was found in this study to be abundant in the 
fungal extracts. It was found in both inactive and active fractions at high levels (Table 1S). From Fig. 2D, it can be seen that unlike the metabolites discovered from the active fractions and extracts, the inactive fractions and extracts share less of the metabolites. However, it is not established how individual metabolites affect the activities.

Statistical methods, such as principal component analysis (PCA) and clustering were also used. PCA was found effective with four factors explaining $79 \%$ of total variance (See Table 2SB). The first principal component (PC) linked metabolites from ORAC and SCAV active fractions together. The fractions active in these two in vitro microplate methods for antioxidant potential have 15 common metabolites, which is $40 \%$ of the metabolites in ORAC ${ }^{\text {act }}$ and $17 \%$ of the metabolites in SCAV ${ }^{\text {act }}$ fractions (Fig. 2). Additionally, the metabolites from DNA damage biosensor fractions seem to be linked to this PC (with a semi-strong loading 0.43). The second PC linked metabolites from antioxidant and DNA damage biosensor test active fractions together. The fractions active in these in vivo biosensor methods contain 51 metabolites in common, which is $78 \%$ of the metabolites in DNA ${ }^{\text {act }}$ and $54 \%$ of the metabolites in antiox ${ }^{\text {act }}$ fractions (Fig. 2). The principal components PC3 and PC4 were formed by the oxidative stress biosensor test (ox) and the PD cell model test, respectively. The explanation of PC3 is likely linked to the choice of making ox biosensor test active metabolite ion abundancies negative and inactive ones positive, in order to emphasize the negative correlation with the antiox biosensor test. Cell model test PD also differs from all the other methods and is therefore likely to form its own PC.

The activities were divided into 19 clusters containing from 1 to 52 metabolites with different bioactivities (see Table 2). The most informative content was reached with bioactive clusters showing activity in only one of the antioxidant tests (Fig. 3). Three clusters contained 13 metabolites found only from the SCAV test active fractions, other three clusters contained 16 metabolites exclusively from antioxidant active biosensor test (antiox ${ }^{\text {act }}$ ) fractions and one cluster contained ten metabolites found only from the ORAC active fractions (Table 2). Based on tentative identifications, these antioxidant active clusters all had dipeptides with Leu or Ile amino acid residues. SCAV test active clusters had six of these dipeptides putatively amnotated (Leu or Ile and Thr, Ser, Gln, Met, Ala, or Glu). Biosensor antioxidant 
test active clusters had four potential dipeptides with Leu or Ile (Leu or Ile and Glu, Val, Leu, or Asp) whereas ORAC test active clusters had three (Leu or Ile and Asp, Arg or Lys) (Fig. 3). When considering these tentative identifications, the active clusters may contain Leu or Ile dipeptides with negatively charged side chains (Asp and Glu) although differences can also be seen. The SCAV test active clusters potentially contain Leu or Ile amino acids with polar uncharged (Thr, Ser, Gln) or hydrophobic (Met and Ala) side chains. Biosensor antiox active potential Leu or Ile dipeptides suggest hydrophobic (Val and Leu) side chains and ORAC active fractions suggest positively charged (Arg and Lys) side chains. Both SCAV and biosensor antioxidant test active fractions, thus, potentially contain hydrophobic side chains. These tests measure the inhibition of $\mathrm{H}_{2} \mathrm{O}_{2}$. However, the difference between them is that the SCAV test measures the ability of a compound to scavenge $\mathrm{H}_{2} \mathrm{O}_{2}$ before it oxidizes an iron complex, while in the biosensor test, the active compound must be able to protect the bacterial biosensor strain from the harmful effects of $\mathrm{H}_{2} \mathrm{O}_{2}$ in vivo, for example by quenching.

In this study, it was shown that extracts from endophytic fungi grown in vitro exhibit antioxidant and antimicrobial properties, but it was not possible to identify any individual compounds which would induce the bioactive properties. Additionally, it was found that the fungal extracts and fractions contained a plethora of metabolites and these three endophytic fungi had a high similarity in their metabolite composition, while the bioactivities differ between them. For example, with the ORAC test, the extracts were active even if the fractions were not (see Table 1). These factors could indicate a possibility that synergetic effects of the metabolites are responsible for their bioactivities found in this study. Similar conclusions on synergistic effects for forest-derived bioactive extracts have been proposed for example by Willför et al. [36], who found that the antioxidant potency of conifer knotwood extracts was higher than that of their predominant pure compounds. Alternative explanations could include concentration differences between the crude extracts and fractions, or possible decomposition induced by extra handling such as lyophilization. However, it is important to note that using only aqueous extracted partial metabolome causes limitations to the conclusions of this study. Additionally, a major part of 
similarity of the metabolomes of the fungal species. Numerous studies have shown a connection between oxidative stress and drought in plants [37-39]. The endophytic fungi of this study were obtained from dried peatlands, which are harsh environments causing stress via factors such as alternating water levels. Endophytic fungi and dark septate endophytic species are known to improve the host plant stress tolerance and growth as well as increase the water and nutrient uptake of the host [5]. However, less is known about the mechanism behind the phenomenon. Suggested explanations involve phytohormone production and/or root biomass extension, which leads to increased water and nutrient intake [5]. In this study, the waterextracted endophytic fungi were found to contain numerous potentially bioactive metabolites. In conclusion, we propose that the synergetic effects of various bioactive metabolites produced by the endophytic symbionts could potentially offer an additional explanation to the mechanism behind the increasing stress tolerance of the host plant.

\section{Materials and Methods}

\section{Reagents}

Ala-Phe, Ala-Tyr, Asp-Phe (methyl ester), Leu-Leu (acetate), Pro-Leu, uridine and L-tyrosine, were obtained from Sigma, each with purity $\geq 98 \%$. L-Ala-L-Gln (HPLC grade), L-Ala-L-Trp, Gly-L-Phe (HPLC grade), and L-Leu-L-Ala (hydrate) were obtained from TCI, with purity >98\%. L-(-)tryptophan (purity $>99 \%$ ) was purchased from Acros Organics/Thermo and ciprofloxacin (hydrochloride) from Bayer. Hydrogen peroxide and citric acid (monohydrate, purity >99\%) were obtained from Merck, and ethanol from Altia. L-Ascorbic acid was obtained from VWR.

\section{Fractionation of the fungal extracts}

The fungal mycelia cultivation and extraction procedure are described in Tienaho et al. [6]. In brief, the sterile fungal mycelium was cultivated on Hagem agar Petri dishes on a cellophane membrane and extracted with deionized, sterile filtered and boiling water. Cell debris was removed by centrifuging and supernatant was finally sterile filtered before storing at $-80^{\circ} \mathrm{C}$. Fractionation was performed for the thawed extracts with a Shimadzu Prominence high-performance liquid chromatography (HPLC) system (Shimadzu). A total of 
$100 \mu \mathrm{L}$ of the aqueous fungal extract was injected to the HPLC by the autosampler SIL-20AC. Pumps used were LC-20AP with the flow rate of $15 \mathrm{~mL} / \mathrm{min}$. The column used was Waters XBridge reverse phase C18 preparative column $(5.0 \mu \mathrm{m} \times 19 \mathrm{~mm} \times 150 \mathrm{~mm})$, which was maintained at $30{ }^{\circ} \mathrm{C}$ in a CTO-20AC column oven. A photodiode array detector (SPD-M20A) was used in the range of 200-600 nm (220 nm as the main wavelength) and the fractions were collected with FRC-10A collector. The mobile phase consisted of water filtered through $0.22 \mu \mathrm{m}$ Millipak 40 membrane (Millipore, Merck) (eluent A) and HPLC-grade methanol (Merck) (eluent B). Separation was accomplished using a gradient method from $100 \%$ water to $50 \%$ methanol and back to $100 \%$ water over a duration of $15 \mathrm{~min}$. All the peaks in the chromatogram were collected and the number of peaks varied from 13 to 15 per fungus. The fractionation was repeated five times in order to collect a sufficient amount of the material for further processing. The collected fractions were then dried using a vacuum centrifuge with a cooling unit (Rotational-Vacuum-Concentrator 2-18 with Cold Trap 02-50, Martin Christ). Before analysis, the dried fractions were dissolved in $0.5 \mathrm{~mL}$ of sterile purified water.

\section{UPLC-MS analysis and identification}

The detailed metabolite profiling via UPLC-DAD-ESI-Orbitrap-MS and the identification process are both described in Tienaho et al. [6]. Briefly, a phenyl column (Acquity UPLC BEH Phenyl, Waters) was used with the mobile phases of acetonitrile (A) and formic acid in water (B) using gradient elution. The heated ESI source was used both in the negative and positive ion modes and masses were scanned at $\mathrm{m} / \mathrm{z}$ 1502000. Data was processed using the Xcalibur Qual Browser software (version 3.0.63, Thermo Fisher Scientific Inc.) and Compound Discoverer 2.1 SP1 (Thermo Fisher Scientific Inc.) with Chemspider and KEGG databases for identification. Additionally, the SciFinder Scholar database (American Chemical Society, CAS) was used with the substance role Occurrence. 


\section{Bioactivity analysis}

\section{Bacterial strains and experimental procedures}

Recombinant bacterial strains previously described by Belkin et al. [11] and Vollmer et al. [12] were used in this study to screen for compounds generating oxidative stress for the bacteria or possessing antioxidant properties (E. coli DPD2511 (katG'::lux)) and for compounds generating genotoxicity for the bacteria $(E$. coli DPD2794 (recA'::lux)). Both strains were a kind gift from Dr. Robert A. LaRossa, from DuPont Company Central Research and Development. The method described by Tienaho et al. [13] was used with slight modifications. The sample triplicates of volume $10 \mu \mathrm{L}$ and $90 \mu \mathrm{L}$ of the bacterial inoculum were added to the microplate wells. With the antioxidant properties measurement, the sample triplicates of volume $10 \mu \mathrm{L}$ and $10 \mu \mathrm{L}$ of $4 \mathrm{mM}$ (per well) of hydrogen peroxide (the oxidative substance) was added as well as $80 \mu \mathrm{L}$ of bacterial inoculum. The final volume per microplate well was $100 \mu \mathrm{L}$ in each case. The control antioxidant used in this study was ascorbic acid (concentrations per well $2.84 \mathrm{M}$ and $0.28 \mathrm{M}$ in phosphate buffer) and ciprofloxacin was used as the control bacterial DNA damaging agent (concentrations per well $0.3 \mathrm{M}$ and $19 \mathrm{mM}$ ). In the oxidative stress measurement, two concentrations of hydrogen peroxide (4 $\mathrm{mM}$ and $42 \mathrm{mM}$ per well) were used as positive controls and sterile purified water as the negative control in the measurements. The two concentrations of positive control substances were used to verify the function of the biosensor. The produced luminescence was measured with a Chameleon Multilabel (Hidex Oy) microplate reader in counts per seconds (CPS) every five minutes for a total of 20 times and the plate was shaken and kept at $30{ }^{\circ} \mathrm{C}$ between the screenings. The results are expressed with induction factors (IF) calculated by dividing the CPS values of the samples with the value of the negative control. With the antioxidant method, the IF values were compared with those of $\mathrm{H}_{2} \mathrm{O}_{2}$ and considered lower values at the same time point to be an indication of activity.

\section{Hydrogen peroxide scavenging (SCAV) test}

The test was performed according to a ferrous oxidation in xylenol orange (FOX) reagent method by Jiang et al. [14] with minor modifications. The method measures the ability of an antioxidant to act as a transition 
metal chelator and inhibit the Fenton reaction, where $\mathrm{H}_{2} \mathrm{O}_{2}$ oxidizes $\mathrm{Fe}(\mathrm{II})$ into $\mathrm{Fe}$ (III) and forms hydroxyl radicals. The ferric ion forms a colored complex, which can be measured using the absorbance. The concentration of $2 \mathrm{mM} \mathrm{H}_{2} \mathrm{O}_{2}$ (Merck) was mixed with sample solutions (1:1, v/v) and incubated for 30 minutes at room temperature after which $0.2 \mu \mathrm{m}$ filtered and deionized water $(3: 1, \mathrm{v} / \mathrm{v})$ was added to the sample- $\mathrm{H}_{2} \mathrm{O}_{2}$ mixture. Mixtures were vortexed and centrifuged (12 $000 \mathrm{~g}, 5$ minutes) and $10 \mu \mathrm{L}$ of the sample solutions were pipetted in quadruplicates to a translucent microplate (Sarstedt). Quadruplicates of sodium pyruvate (Sigma) with contents $2 ; 1.8 ; 1.4 ; 1 ; 0.7 ; 0.4$ and $0 \mathrm{mg} / \mathrm{mL}$ were used as the positive control substance with the same volume. Before adding the coloring agent, $190 \mu \mathrm{L}$ of a solution consisting of 4.4 mM D(-)-sorbitol (AppliChem) solution without xylenol orange (Sigma) and $2.56 \mathrm{mM}$ ammonium iron (II) sulphate (VWR) in $0.25 \mathrm{mM}$ of sulfuric acid (9:1, v/v, Merck) was added into the wells of one of four sample and control quadruplicates. These blanks were used to minimize the possible effect of the color differences of the sample solutions. The microplate was then inserted into a Varioskan Flash multimode reader (Thermo), which injected $190 \mu \mathrm{L}$ of the FOX solution into the rest of the microplate wells. FOX solution contains $27.8 \mu \mathrm{M}$ of xylenol orange in $4.4 \mathrm{mM}$ of sorbitol and $2.56 \mathrm{mM}$ ammonium ferrous iron (II) sulphate in $0.25 \mathrm{mM}$ of sulfuric acid $(9: 1, \mathrm{v} / \mathrm{v})$. The absorbance of the wells was measured immediately and after 30 minutes at the measured optimum wavelength of $590 \mathrm{~nm}$. The absorbance of the blank wells was subtracted from the absorbance values before calculating the average of the sample and control quadruplicate values. The sample values were compared with the control curve drawn with the sodium pyruvate concentrations and the results are expressed with \%-inhibition. The coefficient of variation (\%) was used to present the measurement error between the sample quadruplicates. Unless stated otherwise, if the results were in the control curve range and gave a \%-inhibition value above zero, the extract and fraction were considered active.

\section{Oxygen radical absorbance capacity (ORAC) test}

The Oxygen Radical Absorbance Capacity (ORAC) test measures the dissociation of fluorescein in the presence of peroxyl radicals ( $\mathrm{ROO} \bullet$ ), which causes a reduction in the fluorescence signal. In order to be 
active in the test, the antioxidant needs to inhibit the dissociation through hydrogen atom transfer. The assay was modified from the method described by Prior et al. [15] and Varioskan Flash multimode reader (Thermo) and 96-well black, opaque microplates (Sarstedt) with two technical replicates of each sample on the plate were used. The reaction mixture contained $25 \mu \mathrm{L}$ of the sample in $0.075 \mathrm{M}$ phosphate buffer $\mathrm{pH}$ 7.5 (Merck), $150 \mu \mathrm{L}$ of $8.16 \times 10^{-5} \mathrm{mM}$ fluorescein (Sigma) and $25 \mu \mathrm{L}$ of 2,2'-azobis(2methylpropionamidine) dihydrochloride (AAPH) (Sigma). The AAPH solution was dispensed by the multimode reader. For each sample, a protocol with a series of dilutions $(1: 1 ; 1: 40 ; 1: 80 ; 1: 160,1: 320, \mathrm{v} / \mathrm{v})$ was used and additional dilutions if needed to adjust the sample concentration to the standard curve. The fluorescence (emission $538 \mathrm{~nm}$; excitation $485 \mathrm{~nm}$ with bandwidth $12 \mathrm{~nm}$ ) was measured 21 times every 2 minutes and shaken between measurements with incubation at $37^{\circ} \mathrm{C}$. Vitamin $\mathrm{E}$ analog, Trolox $0.153 \mathrm{mM}$ (Sigma) concentrations were used as standards and the results were expressed as Trolox equivalents (TE $\mu \mathrm{mol} / \mathrm{L})$. The extracts and fractions were considered active if they produced TE $\mu \mathrm{mol} / \mathrm{L}$ values above 500 .

\section{Parkinson's disease (PD) cell model}

For the screening for activity against Parkinson's disease [19, 40], a cell line SH-SY5Y was used (obtained from American Type Culture Collection (ATCC), CRL 2266). Cells were seeded into black 384 well plates with a clear bottom. Numbers of cells per culture were $4 \mathrm{M}$ cells $/ \mathrm{mL}$ and $1 \mathrm{M}$ cells $/ \mathrm{mL}$. Cells were incubated for $24 \mathrm{~h}$ at $37^{\circ} \mathrm{C}, 5 \% \mathrm{CO}_{2}$. The medium was then removed and replaced by $195 \mu \mathrm{L}$ of fresh medium. Five $\mu \mathrm{L}$ of each sample dilution were pipetted into the plates in two fold series along with $20 \%$ DMSO as a control sample after which the plates were incubated at $37{ }^{\circ} \mathrm{C}, 5 \% \mathrm{CO}_{2}$ for 3 hours. After that, $5 \mu \mathrm{L}$ of 20 $\mu \mathrm{M}$ Rotenone (Sigma, final concentration $500 \mathrm{nM}$ ) was added. The plates were incubated overnight at 37 ${ }^{\circ} \mathrm{C}, 5 \% \mathrm{CO}_{2}$. To measure the mitochondrial membrane potential, JC-1 assay was used. JC-1 (Tebubio) localizes to the inner mitochondrial membrane where it forms monomers or aggregates based on $\Delta \Psi \mathrm{m}$. At high $\Delta \Psi \mathrm{m}$ values JC-1 accumulates sufficiently in the mitochondria, to form aggregates (J-aggregates) that exhibit red fluorescence. On the other hand, at a lower $\Delta \Psi \mathrm{m}$ value, less dye enters mitochondria resulting in monomers that show green fluorescence. Cells were incubated with JC-1 (final concentration $2 \mu \mathrm{M}$ ) in 
the assay buffer $\left(\mathrm{NaCl} 165 \mathrm{mM}, \mathrm{KCl} 4.5 \mathrm{mM}, \mathrm{CaCl}_{2} 2 \mathrm{mM}, \mathrm{MgCl}_{2} 1 \mathrm{mM}\right.$, Hepes $10 \mathrm{mM}$, glucose $10 \mathrm{mM}$, $\mathrm{pH}$ 7.4, Sigma) for $30 \mathrm{~min}$ at $37^{\circ} \mathrm{C}$. The plates were read in a FLIPRTETRA and HCS equipment using excitation/red emission (510-545 nm/ 565-625 nm) and green emission (470 nm/ 510-575 nm). Data obtained for red and green channels were used as ratio red/green.

Age-related macular degeneration (AMD) cell model

In AMD cell model, immortalized human retinal pigment epithelial cells, ARPE-19 (ATCC, CRL2302_FL) [41], were exposed to hydrogen peroxide $\left(\mathrm{H}_{2} \mathrm{O}_{2}\right)$ to induce oxidative injury typical to AMD. The cells were grown in Dulbecco's MEM/Nut MIX F-12 medium (Gibco) on 96-well plates using 10000 cells / well. After $24 \mathrm{~h}$ at $37{ }^{\circ} \mathrm{C}, 5 \% \mathrm{CO}_{2}$ cells were exposed to $400 \mu \mathrm{M}$ hydrogen peroxide (Sigma) with or without the fungal extract. After 1-24 h incubation, cytotoxicity was evaluated with WST-1 assay (Roche) following the manufacturer's instructions. WST-1 assay is based on functions of mitochondrial dehydrogenase enzymes as an indication of cellular growth and viability. A known plant-derived antioxidant, quercetin (100 $\mu \mathrm{M}$; Sigma), was used as a positive control.

\section{Osteoarthritis $(O A)$ cell model}

For the screening of cartilage protecting activities in osteoarthritis, effects on the production of cartilage degrading enzyme matrix metalloproteinase 3 (MMP-3) by immortalized T/C28a2 human chondrocyte cell line were screened [18]. The immortalized chondrocyte cell-line T/C28a2 was obtained from Prof Mary B. Goldring (Harvard Medical School). T/C28a2 chondrocytes is a cell-line established by transfection of primary cultures of juvenile costal chondrocytes with vectors encoding simian virus 40 large $\mathrm{T}$ antigen. Chondrocytes were cultured at $37{ }^{\circ} \mathrm{C}$ in $5 \% \mathrm{CO}_{2}$ atmosphere and grown in DMEM (Sigma-Aldrich) and Ham's F-12 medium (Lonza) (1:1, v/v) containing heat-inactivated fetal bovine serum (10\%) (Lonza), penicillin $(100 \mathrm{U} / \mathrm{mL})$, streptomycin $(100 \mu \mathrm{g} / \mathrm{mL})$, and amphotericin B $(250 \mathrm{ng} / \mathrm{mL})$ (all from Gibco/Life Technologies). Chondrocytes were stimulated with IL-1 $(100 \mathrm{pg} / \mathrm{mL}, \mathrm{R} \& \mathrm{D}$ Systems Europe Ltd) with or without the fungal extract $(10 \mu \mathrm{g} / \mathrm{mL})$. After 24 hours, culture medium samples were collected and stored 
at $-20^{\circ} \mathrm{C}$ until analyzed. MMP-3 production was measured in the culture medium by ELISA (R\&D Systems Europe Ltd). Cytotoxicity of all the samples was ruled out by measuring cell viability using XTT-test (Cell Proliferation Kit II, Roche Diagnostics). Intra-articular glucocorticoid injections are used as an antiinflammatory, symptomatic therapy for OA, and dexamethasone $(1 \mu \mathrm{M}$; Sigma) was used as a positive control.

\section{Principal component analysis and cluster analysis}

The bioactivity data from Table 2 was modified for statistical analysis in order to simplify the process. Because the metabolites in Table 2 can be found in active or inactive fractions but not both, the active fractions were chosen to be positive and inactive negative for antiox, DNA, SCAV, ORAC and PD. For the ox biosensor test, the active ones were chosen to be negative and inactive ones positive, in order to emphasize the negative correlation with the antiox biosensor test.

Principal component analysis (PCA) was used to group variables from two data sets: fractions and bioactivity tests. The purpose was to reveal the possible internal structures that best explain the total variance of the data sets. The first principal component (PC) accounts for most of the variability, and the last PC for the least, and therefore, only a few PCs are needed to contain most of the information.

The amount of principal components (PC) was determined based on the Scree test, the proportion of variation explained, and the interpretability of PCs. Six PCs were chosen for fraction variables and four PCs to bioactivity test variables, respectively. In the first case, orthogonal Varimax rotation was used (Table 2SA). The sampling adequacies, tested with the Kaiser-Melkin-Olkin (KMO) measure, were acceptable, with KMO values of 0.74 and 0.59 , respectively. The first data was not ideal for PCA, because there were only six quite different variables. In the second case, non-orthogonal Promax rotation was used because of relatively high inter-correlations of PCs. Half of inter-factor correlations exceeded 0.32 ranging between 0.00 and 0.53 (Table 2SB). Non-orthogonal rotation could be used, when the inter-factor correlations of PCs mostly exceed 0.32 [42]. The internal consistencies of the factors, measured using Cronbach's alpha, ranged from acceptable to excellent (0.61-0.91). 
Both data sets were clustered from raw data. The metabolites were clustered with Ward's method [43], which starts with $n$ clusters of size one and continues until all the observations are included in one cluster. Data sets were challenging for clustering due to many divergent observations (outliers), and therefore different clustering techniques were tested. Although Ward's method is sensitive to outliers, it was found to be the most interpretable. To reduce distortion by outliers, the most problematic metabolites were omitted from clustering. The squared Euclidean distances between data points were used. The number of clusters was selected based on the dendrogram, the pseudo $t^{2}$ criterion, ' and the variation in $R^{2}$ values [44]. Statistical analyses were performed with the SAS Enterprise Guide 7.4. (SAS).

\section{Supporting information}

All the metabolites found in the extracts and fractions (Table 1S) and principal component analysis

(Table 2SA and 2SB) are available as Supporting information.

\section{Acknowledgements}

We thank Anneli Käenmäki, Hanna Leppälammi and Eeva Pihlajaviita for proficient and competent laboratory assistance. We also thank COST Action FA1103: Endophytes in Biotechnology and Agriculture for the short-term scientific mission funding of Jenni Tienaho. This study has been financially supported by the European Regional Development Fund (project code A71142) as well as the town of Parkano and SASKY municipal education and training consortium. Natural Resources Institute Finland and Tampere University of Technology are also warmly acknowledged for their financial support. In addition, Jenni Tienaho is grateful to Kone Foundation for a personal grant.

\section{Conflict of interest}

The authors declare no conflict of interest.

\section{References}

[1] Stone J, Bacon C, White J. An Overview of Endophytic Microbes: Endophytism defined. In: Bacon CW, White JF Jr, editors. Microbial endophytes, 1st edition. New York: Marcel Dekker, Inc.; 2000: $3-29$ 
[2] Tan RX, Zou WX. Endophytes: a rich source of functional metabolites. Nat Prod Rep 2001; 18: 448459

[3] Strobel G, Daisy B, Castillo U, Harper J. Natural products from endophytic microorganisms. J Nat Prod 2004; 67: 257-268

[4] Firáková S, Šturdíková M, Múčková M. Bioactive secondary metabolites produced by microorganisms associated with plants. Biologia 2007; 62: 251-257

[5] Li X, He X, Hou L, Ren Y, Wang S, Su F. Dark septate endophytes isolated from a xerophyte plant promote the growth of Ammopiptanthus mongolicus under drought condition. Sci Rep 2018; 8: 7896

[6] Tienaho J, Karonen M, Muilu-Mäkelä R, Wähälä K, Leon Denegri E, Franzén R, Karp M, Santala V, Sarjala T. Metabolic Profiling of Water-Soluble Compounds from the Extracts of Dark Septate Endophytic Fungi (DSE) Isolated from Scots Pine (Pinus sylvestris L.) Seedlings Using UPLCOrbitrap-MS. Molecules 2019; 24: 2330

[7] Shashidhar MG, Giridhar P, Sankar KU, Manohar B. Bioactive principles from Cordyceps sinensis: A potent food supplement - A review. J Funct Foods 2013; 5: 1013-1030

[8] Kaarniranta K, Ryhänen T, Karjalainen H, Lammi M, Suuronen T, Huhtala A, Kontkanen M, Teräsvirta M, Uusitalo H, Salminen A. Geldanamycin increases 4-hydroxynonenal (HNE)-induced cell death in human retinal pigment epithelial cells. Neurosci Lett 2005; 382: 185-190

[9] Vuolteenaho K, Moilanen T, Knowles RG, Moilanen E. The role of nitric oxide in osteoarthritis. Scand J Rheumatol 2007; 36: 247-258

[10] Dias V, Junn E, Mouradian MM. The role of oxidative stress in Parkinson's disease. J Parkinson Dis 2013; 3: 461-491

[11] Belkin S, Van Dyk TK, Vollmer AC, Smulski DR, LaRossa RA. Monitoring subtoxic environmental hazards by stress-responsive luminous bacteria. Environ Toxicol Water Qual 1996; 11: 179-185

[12] Vollmer AC, Belkin S, Smulski DR, Van Dyk TK, LaRossa RA. Detection of DNA damage by use of Escherichia coli carrying recA'::lux, uvrA'::lux, or alkA'::lux reporter plasmids. Appl Environ Microbiol 1997; 63: 2566-2571

[13] Tienaho J, Sarjala T, Franzén R, Karp M. Method with high-throughput screening potential for antioxidative substances using Escherichia coli biosensor kat $G^{\prime}:$ :lux. J Microbiol Methods 2015; 118: $78-80$

[14] Jiang Z-Y, Woollard ACS, Wolff SP. Hydrogen peroxide production during experimental protein glycation. FEBS 1990; 268: 69-71

[15] Prior RL, Hoang H, Gu L, Wu X, Bacchiocca M, Howard L, Hampsch-Woodill M, Huang D, Ou B, Jacob R. Assays for hydrophilic and lipophilic antioxidant capacity (oxygen radical absorbance capacity (ORAC)) of plasma and other biological and food samples. J Agric Food Chem 2003; 51: 3273-3279

[16] Aapola U, Viitala K, Potila H, Savonen E-M, Huhtala A, Sarjala T, Uusitalo H. Endophytic fungus Phialophora lignicola Extract Efficiently Protects ARPE-19 Cells against Oxidative Stress. Invest Ophthalmol Vis Sci 2011; 52(14): 5656

[17] Mannerström M, Zorn-KruppaM, Diehl H, Engleke M, Toimela T, Mäenpää H, Huhtala A, Uusitalo H, Salminen L, Pappas P, Marselos M, Mäntylä M, Mäntylä E, Tähti H. Evaluation of the cytotoxicity of selected systemic and intravitreally dosed drugs in the cultures of human retinal pigment epithelial cell line and of pig primary retinal pigment epithelial cells. Toxicol In Vitro 2002; 16(2): 193-200 
[18] Goldring MB, Birkhead JR, Suen LF, Yamin R, Mizuno S, Glowacki J, Arbiser JL, Apperley JF. Interleukin-1 beta-modulated gene expression in immortalized human chondrocytes. J Clin Invest 1994; 94(6): 2307-2316

[19] de Pedro N, Cautain B, Cantizani J, Rodriguez L, Vicente F, Tualsi R, Koyyalamudi SR. In vitro neuroprotective effects of seven natural products against rotenone-induced toxicity in a SH-SY5Y neuroblastoma cells model for Parkinson's disease. Pharmacologia 2016; 7: 361-370

[20] Watt K, Christofi N, Young R. The detection of antibacterial actions of whole herb tinctures using luminescent Escherichia coli. Phytother Res 2007; 21: 1193-1199

[21] Bartolome A, Macalino B, Pastoral IL, Sevilla F. Antioxidant assay using engineered bioluminescent Eschericia coli. In: Savitsky AP, Wachter R, editors. Proceedings of SPIE Vol. 6098: Genetically engineered probes for biomedical applications, San Jose, California, United States; 2006: 60980J

[22] Apak R, Gorinstein S, Böhm V, Schaich KM, Özyürek M, Güçlü K. Methods of measurement and evaluation of natural antioxidant capacity/activity (IUPAC Technical Report). Pure Appl Chem 2013; 85: 957-998

[23] Carrasco-Castilla J, Hernández-Álvarez AJ, Jiménez-Martínez C, Jacinto-Hernández C, Alaiz M, Girón-Calle J, Vioque J, Dávila Ortiz G. Antioxidant and metal chelating activities of peptide fractions from phaseolin and bean protein hydrolysates. Food Chem 2012; 135: 1789-1795

[24] Hernández-Ledesma B, Dávalos A, Bartolomé B, Amigo L. Preparation of antioxidant enzymatic hydrolysates from $\alpha$-lactalbumin and $\beta$-lactoglobulin. Identification of active peptides by HPLCMS/MS. J Agric Food Chem 2005; 53: 588-593

[25] Saiga A, Tanabe S, Nishimura T. Antioxidant activity of peptides obtained from porcine myofibrillar proteins by protease treatment. J Agric Food Chem 2003; 51: 3661-3667

[26] Chen H-M, Muramoto K, Yamauchi F. Structural analysis of antioxidative peptides from soybean $\beta$ conglycinin. J Agric Food Chem 1995; 43: 574-578

[27] Sánchez A, Vázquez A. Bioactive peptides: A review. Food quality and safety 2017; 1: 29-46

[28] Koskimäki JJ, Kajula M, Hokkanen J, Ihantola E-L, Kim JH, Hautajärvi H, Hankala E, Suokas M, Pohjanen J, Podolich O, Kozyrovska N, Turpeinen A, Pääkkönen M, Mattila S, Campbell BC, Pirttilä A-M. Methyl-esterified 3-hydroxybutyrate oligomers protect bacteria from hydroxyl radicals. Nat Chem Biol 2016; 12: 332-338

[29] Pocsi I, Prade RA, Penninckx MJ. Glutathione, Altruistic metabolite in fungi. Adv Microb Physiol 2004; 49

[30] Salas CE, Badillo-Corona JA, Ramirez-Sotelo G, Oliver-Salvador C. Biologically active and antimicrobial peptides from plants. Biomed Res Int 2015; 1-11

[31] Bondaryk M, Staniszewska M, Zielinska P, Urbanczyk-Lipkowska Z. Natural antimicrobial peptides as inspiration for design of a new generation antifungal compounds. J Fungi 2017; 3: 1-36

[32] Kombrink A, Tayyrov A, Essig A, Stöckli M, Micheller S, Hintze J, van Heuvel Y, Dürig N, Lin CW, Kallio PT, Aebi M, Künzler M. Induction of antibacterial proteins and peptides in the coprophilous mushroom Coprinopsis cinerea in response to bacteria. ISME J 2018; 13: 588-602

[33] Ries S, Wert V, O'Leary NFD, Nair M. 9- $\beta$-L(+) Adenosine: A new naturally occurring plant growth substance elicited by triacontanol in rice. Plant Growth Regul 1990; 9: 263-273

[34] Pirttilä AM. Endophytic bacteria in tree shoot tissues and their effects on host. In: Pirttilä AM, Frank AC, editors. Endophytes of Forest Trees: Biology and Applications, Forestry Sciences Vol. 80. Heidelberg: Springer Verlag; 2011: 139-149 
[35] Osugi A, Sakakibara H. Q\&A: How do plants respond to cytokinins and what is their importance? BMC Biol 2015; 13: 102

[36] Willför SM, Ahotupa MO, Hemming JE, Reunanen MH, Eklund PC, Sjöholm RE, Eckerman CS, Pohjamo SP, Holmbom BR. Antioxidant activity of knotwood extractives and phenolic compounds of selected tree species. J Agric Food Chem 2003; 51: 7600-7606

[37] Jaleel CA, Manivannan P, Sankar B, Kishorekumar A, Gopi R, Somasundaram R, Panneerselvam R. Induction of drought stress tolerance by ketoconazole in Catharanthus roseus is mediated by enhanced antioxidant potentials and secondary metabolite accumulation. Colloids Surf B 2007; 60: 201-206

[38] Miller G, Suzuki N, Ciftci-Yilmaz S, Mittler R. Reactive oxygen species homeostasis and signaling during drought and salinity stresses. Plant Cell Environ 2010; 33: 453-467

[39] Obata T, Fernie AR. The use of metabolomics to dissect plant responses to abiotic stresses. Cell Mol Life Sci 2012; 69: 3225-3243

[40] de Pedro N, Cantizani J, Ortiz-López FJ, González-Menéndez V, Cautain B, Rodríguez L, Bills GF, Reyes F, Genilloud O, Vicente F. Protective effects of isolecanoric acid on neurodegenerative in vitro models. Neuropharmacology 2016; 101: 538-548

[41] Dunn KC, Aotaki-Keen AE, Putkey FR, Hjelmeland LM. ARPE-19, a human retinal pigment epithelial cell line with differentiated properties. Exp Eye Res 1996; 62(2): 155-169

[42] Tabachnick BG, Fidell LS. Using multivariate statistics, 5th edition. Boston: Allyn \& Bacon; 2007

[43] Ward JH. Hierarchical grouping to optimize an objective function. J Am Stat Assoc 1963; 58: 236244

[44] Yeo D, Truxillo C. Applied Clustering Techniques Course Notes. Cary: SAS Institute Inc.; 2005 


\section{Legends for figures}

Fig. 1 An example of the bioactivity results with E. coli DPD2511 biosensor responding to oxidative stress: the induction factors (IF, compared with water blank) of the fraction $2(\mathrm{~F} 2)$ from the fungus R extract. Three different concentrations $(5.7,11.4$, and $22.8 \mathrm{mg} / \mathrm{mL})$ of the fraction were tested. The symbols present the average values of three replicates and error bars are the coefficient of variation (CV\%) between the replicates. Positive control $\mathrm{H}_{2} \mathrm{O}_{2}$ was used in the test and signal maxima were IF 72 at 15 minutes for $4 \mathrm{mM}$ solution and IF 312 at 25 minutes for $42 \mathrm{mM}$ solution.

Fig. 2 The Venn diagrams about the metabolite distribution in the different fractions and extracts with bioactivities and inactivities. (A) Organized according to the oxygen radical absorbance capacity (ORAC) and hydrogen peroxide scavenging (SCAV) and cell model for Parkinson's disease (PD) activities and inactivities. (B) Organized according to the biosensor tests with E. coli DPD2511 oxidative stress (ox) and antioxidant (antiox) as well as $E$. coli DPD2794 DNA damage (DNA). (C) Organized according to the $E$. coli DPD2511 oxidative stress (ox), SCAV and ORAC. (D) Organized according to the metabolites found only in inactive fractions and extracts. The pie charts show roughly the type of metabolites that were found: $\mathrm{P}=$ peptides, $\mathrm{O}=$ other and $\mathrm{U}=$ unknown.

Fig. 3 The clusters with compounds found from fractions with only one activity: DNA ${ }^{\text {act }}$, ORAC $^{\text {act }}$, SCAV $^{\text {act }}$ or antiox ${ }^{\text {act }}$ are shown, compound numbers, clusters and activities are shown in Table 2. See also Table 2 footnotes for the identities of peptides. The framed dipeptides potentially have Leu or Ile in their structures. The side chain properties vary with these preliminary identifications. 
Table 1 The detected bioactive properties of the fungal extracts A (A. applanata), R (P. fortinii) and S16 (H. cephalosporioides or C. mutabilis) and for their 19 bioactive fractions (F1-F15). The 23 fractions showing no activities are not listed. The activities of the extracts are highlighted with a gray color. Bioactivity is indicated with + and inactivity with -. Controls used were $\mathrm{H}_{2} \mathrm{O}_{2}$ (positive) and water blank for oxidative stress with E. coli DPD2511; ciprofloxacin (positive) and water blank for DNA damage with E. coli DPD2794; in both tests active if IF > 1 and dose responsive signals. $\mathrm{H}_{2} \mathrm{O}_{2}$ (negative) and ascorbic acid (positive) were used as controls for antioxidant activity with E. coli DPD2511 and the rise in the \%inhibition of $\mathrm{H}_{2} \mathrm{O}_{2}$ within 3 or more induction timepoints was considered activity. SCAV (=Hydrogen peroxide scavenging) results are compared against sodium pyruvate control curve (positive); + if results were in the control curve range and gave a \%-inhibition value above zero and ORAC (=Oxygen radical absorbance capacity) results are compared against Trolox control (positive); + if $\mu \mathrm{mol} / \mathrm{L}$ values above 500. Cell model tests (PD, AMD, OA) were conducted for the fungal extracts only (threshold values and controls, see Materials and Methods).

\begin{tabular}{|c|c|c|c|c|c|c|c|c|}
\hline & $\begin{array}{c}\text { Oxidative } \\
\text { stress with } E . \\
\text { coli DPD2511 }\end{array}$ & $\begin{array}{c}\text { Antioxidant } \\
\text { activity with } E . \\
\text { coli DPD2511 }\end{array}$ & $\begin{array}{c}\text { DNA damage } \\
\text { with E. coli } \\
\text { DPD2794 }\end{array}$ & SCAV & ORAC & PD & AMD & OA \\
\hline A & - & + & + & + & + & + & - & - \\
\hline F2 & + & - & + & + & - & & & \\
\hline F3 & + & + & + & + & - & & & \\
\hline F5 & - & + & + & + & - & & & \\
\hline F13 & - & + & - & - & - & & & \\
\hline R & - & + & + & + & + & - & - & - \\
\hline F2 & + & - & + & + & - & & & \\
\hline F3 & + & + & + & - & - & & & \\
\hline F4 & - & + & + & + & - & & & \\
\hline F7 & + & - & - & + & - & & & \\
\hline F10 & - & + & + & + & - & & & \\
\hline F11 & + & - & - & - & - & & & \\
\hline F13 & - & + & - & - & - & & & \\
\hline F14 & - & + & + & + & - & & & \\
\hline F15 & - & + & - & + & - & & & \\
\hline S16 & + & + & + & + & + & - & - & - \\
\hline F1 & - & + & - & + & - & & & \\
\hline F2 & + & - & + & - & + & & & \\
\hline F3 & + & + & - & - & + & & & \\
\hline F7 & + & - & - & - & + & & & \\
\hline F13 & - & + & + & + & + & & & \\
\hline F14 & + & - & + & + & + & & & \\
\hline
\end{tabular}


Table 2 The metabolites in the active (act) or inactive (inact) fractions and extracts [6]. The bolded metabolites were tested using hydrogen peroxide scavenging (SCAV) and oxygen radical absorbance capacity (ORAC) tests and these results are shown in Table 3. The full list of all discovered metabolites is shown in Table 1S. Unidentified metabolites are shown with measured exact masses. CL = cluster numbers (1-19) of the metabolites, $-=$ outlier. The symbol $\mathrm{x}$ denotes that the listed metabolite has been putatively annotated from the extracts and fractions showing the listed biological activity.

\begin{tabular}{|c|c|c|c|c|c|c|c|c|c|c|c|c|c|c|}
\hline & & & & E. col & PD2 & & & $\begin{array}{l}\text { coli } \\
2794\end{array}$ & & & & & & \\
\hline 1 & 5 & 217.97572 & & & & & $\mathrm{x}$ & & & & & & & \\
\hline 2 & 1 & 387.94673 & & & & & $\mathrm{x}$ & & & & & & & \\
\hline 3 & 5 & 273.96623 & & & & & $\mathrm{x}$ & & & & & & & \\
\hline 5 & 1 & 307.21086 & $\mathrm{x}$ & & & $\mathrm{x}$ & $\mathrm{x}$ & & & & & & & \\
\hline 6 & 12 & Hexosearginine & & & $\mathrm{x}$ & & & & & & & & & \\
\hline 7 & 1 & Ala-Arg or Arg-Ala & & & $\mathrm{x}$ & & & & & & $\mathrm{x}$ & & & $\mathrm{x}$ \\
\hline 8 & 4 & Ace-Ala-Arg-Ala-NMe & & & $x$ & & & & & & & & & \\
\hline 9 & 1 & Ala-Gln & $\mathrm{x}$ & & & & & & & & & & & \\
\hline 10 & 1 & Saccharopine or isomer & $\mathrm{x}$ & & & $\mathrm{x}$ & $\mathrm{x}$ & & & & & & & \\
\hline 14 & 1 & Ala-Glu or Glu-Ala or Heliopine & $\mathrm{x}$ & & & & & & & & & & & \\
\hline 15 & 1 & Thr-Gln or Gln-Thr & $\mathrm{x}$ & & $\mathrm{x}$ & & & & & & $\mathrm{x}$ & & & \\
\hline 16 & 3 & 440.09453 & & & $\mathrm{x}$ & & & & & & & & & \\
\hline 17 & 8 & Acetylhistidine & & & $\mathrm{x}$ & & $\mathrm{x}$ & & $\mathrm{x}$ & & & & & $\mathrm{x}$ \\
\hline 18 & 5 & Ser-Val or Val-Ser & & & $\mathrm{x}$ & & $\mathrm{x}$ & & $\mathrm{x}$ & & & & & $\mathrm{x}$ \\
\hline 19 & 1 & $2 \mathrm{x}$ Valine $^{\mathrm{a}}$ & & & & & & & & & & & & $\mathrm{x}$ \\
\hline 20 & 1 & Pro-Ala & $\mathrm{x}$ & & $\mathrm{x}$ & & & & & & $\mathrm{x}$ & & & \\
\hline
\end{tabular}




\begin{tabular}{|c|c|c|c|c|c|c|c|c|c|c|c|c|c|}
\hline 21 & 5 & Dipeptide $^{\mathrm{c}}$ or Lysopine or Rideopine & & & $\mathrm{x}$ & & $\mathrm{x}$ & & $\mathrm{x}$ & & & & \\
\hline 22 & 5 & Dipeptide $^{\mathrm{d}}$ & & & $\mathrm{x}$ & & $\mathrm{x}$ & & $\mathrm{x}$ & & & & \\
\hline 23 & 2 & Nicotinamide riboside & & & $\mathrm{x}$ & & $\mathrm{x}$ & & $\mathrm{x}$ & & & & \\
\hline 24 & 3 & 352.14790 & & & $\mathrm{x}$ & & & & & & & & \\
\hline 25 & 1 & Acetylglucosaminylserine & $\mathrm{x}$ & & & & & & & & & & \\
\hline 26 & 1 & Asp-Val or Val-Asp & & & $\mathrm{x}$ & & & & & & & & $\mathrm{x}$ \\
\hline 27 & 10 & 322.13713 & & & $\mathrm{x}$ & & $\mathrm{x}$ & & & & & $\mathrm{x}$ & \\
\hline 28 & - & Guanine & & & & & & & $\mathrm{x}$ & & & & $\mathrm{x}$ \\
\hline 29 & - & Ala-Thr or Thr-Ala & & & $\mathrm{x}$ & & & & & & & & \\
\hline 30 & 5 & Dipeptide $^{\mathrm{c}}$ or Lysopine or Rideopine & & & $\mathrm{x}$ & & $\mathrm{x}$ & & $\mathrm{x}$ & & & & $\mathrm{x}$ \\
\hline 31 & 5 & UDP-galactose & & & & & $\mathrm{x}$ & & & & & & \\
\hline 32 & 4 & Dipeptide $^{\mathrm{e}}$ & & & $\mathrm{x}$ & & & & & & & & \\
\hline 33 & 2 & Dipeptide $^{\mathrm{e}}$ & & & $\mathrm{x}$ & & & & & & & & \\
\hline 34 & 8 & Hexosevaline & & & $\mathrm{x}$ & & $\mathrm{x}$ & & $\mathrm{x}$ & & & & \\
\hline 35 & 6 & 287.15767 & & & & & & & $\mathrm{x}$ & & & & \\
\hline 36 & 2 & 239.89826 & & & $\mathrm{x}$ & & $\mathrm{x}$ & & & & & & \\
\hline 37 & 1 & UDP-galactosamine & $\mathrm{x}$ & & $\mathrm{x}$ & & & & & & & & \\
\hline 38 & 1 & AMP or dGMP & & & & & & & & & & & $\mathrm{x}$ \\
\hline 39 & 2 & Ser-Val or Val-Ser & & & $\mathrm{x}$ & & $\mathrm{x}$ & & $\mathrm{x}$ & & & & \\
\hline 40 & 9 & Dipeptide $^{f}$ & & & & & & & & & $\mathrm{x}$ & & \\
\hline 41 & 14 & Tripeptide/peptide ${ }^{g}$ & & & & & $\mathrm{x}$ & & & & & & \\
\hline 42 & 18 & Di/tripeptide ${ }^{\mathrm{h}}$ & $\mathrm{x}$ & & & $\mathrm{x}$ & & $\mathrm{x}$ & & & & & \\
\hline 43 & 2 & 239.89876 & & & $\mathrm{x}$ & & $\mathrm{x}$ & & & & & & \\
\hline 44 & 9 & Dipeptide $^{\mathrm{b}}$ & & & & & & & & & $\mathrm{x}$ & & \\
\hline 45 & 1 & UDP-glucoseamine & $\mathrm{x}$ & & $\mathrm{x}$ & & & & & $\mathrm{x}$ & & & \\
\hline 46 & 1 & \begin{tabular}{|l|} 
Disaccharide \\
\end{tabular} & & & & & $\mathrm{x}$ & & & & & & \\
\hline 47 & 14 & Tripeptide/peptide ${ }^{g}$ & & & & & $\mathrm{x}$ & & & & & & \\
\hline 48 & 1 & 408.17357 & $\mathrm{x}$ & & $\mathrm{x}$ & & & & & & & & \\
\hline 49 & 2 & Di/tripeptide ${ }^{\mathrm{h}}$ & & $\mathrm{x}$ & & & & & & & & & \\
\hline 50 & 1 & Dipeptide $^{f}$ & & & & & & & & & $\mathrm{x}$ & & $\mathrm{x}$ \\
\hline 51 & 13 & Tyrosine (Tyr) & & & & & & & $\mathrm{x}$ & & & & \\
\hline
\end{tabular}




\begin{tabular}{|c|c|c|c|c|c|c|c|c|c|c|c|}
\hline 52 & 1 & Pseudouridine & $\mathrm{x}$ & & $\mathrm{x}$ & & & $\mathrm{x}$ & & & \\
\hline 53 & 10 & Dipeptide $^{\mathrm{e}}$ & & & $\mathrm{x}$ & $\mathrm{x}$ & & & & & \\
\hline 54 & 8 & Dipeptide $^{b}$ & & & $\mathrm{x}$ & $\mathrm{x}$ & $\mathrm{x}$ & & $\mathrm{x}$ & & \\
\hline 55 & 1 & Acetylglutamic acid & & & & $\mathrm{x}$ & & & & & $\mathrm{x}$ \\
\hline 56 & 7 & Dipeptide $^{i}$ & & & & & $\mathrm{x}$ & & & & \\
\hline 57 & 10 & Asp-Val or Val-Asp & & & $\mathrm{x}$ & $\mathrm{x}$ & & & & & \\
\hline 58 & 1 & 273.08439 & $\mathrm{x}$ & & & & & & & & \\
\hline 59 & 1 & Acetylglutamic acid & $\mathrm{x}$ & & & & & & & & \\
\hline 60 & 10 & Acetylcitrulline & & & $\mathrm{x}$ & $\mathrm{x}$ & & & & & \\
\hline 61 & 11 & Dipeptide $^{f}$ & & & $\mathrm{x}$ & $\mathrm{x}$ & $\mathrm{x}$ & & $\mathrm{x}$ & & \\
\hline 62 & 2 & 2',3'-cUMP or 3',5'-cUMP & & & $\mathrm{x}$ & $\mathrm{x}$ & $\mathrm{x}$ & & & & \\
\hline 63 & 5 & 523.13210 & & $\mathrm{x}$ & $\mathrm{x}$ & $\bar{x}$ & $\mathrm{x}$ & & & & \\
\hline 64 & 8 & Uridine & & & $\mathrm{x}$ & $\mathrm{x}$ & $\mathrm{x}$ & & & & \\
\hline 65 & 1 & dAMP & & & & & $\mathrm{x}$ & & & & $\mathrm{x}$ \\
\hline 66 & 2 & Ala-Tyr & & & & & $\mathrm{x}$ & & & & \\
\hline 67 & 4 & Dipeptide $^{j}$ & & & $\mathrm{x}$ & & & & & & \\
\hline 68 & 6 & Leu-Ala & & & & & $\mathrm{x}$ & & & & \\
\hline 69 & 2 & Pro-Val or Val-Pro & & & $\mathrm{x}$ & & $\mathrm{x}$ & & & & \\
\hline 70 & 1 & Nicotinamide adenine dinucleotide & $\mathrm{x}$ & & & & & & $\mathrm{x}$ & & \\
\hline 71 & 10 & Dipeptide $^{j}$ & & & $\mathrm{x}$ & $\mathrm{x}$ & & & & & \\
\hline 72 & 2 & 408.17412 & & & $\mathrm{x}$ & $\mathrm{x}$ & & & & $\mathrm{x}$ & \\
\hline 73 & 5 & Glutathione dimer & & & $\mathrm{x}$ & & $\mathrm{x}$ & & & & \\
\hline 74 & 2 & 408.17412 & & & $\mathrm{x}$ & & $\mathrm{x}$ & & & $\mathrm{x}$ & \\
\hline 75 & 9 & Ser-Tyr or Tyr-Ser & & & & & & & $\mathrm{x}$ & & \\
\hline 76 & 14 & Disaccharide & & & & $\mathrm{x}$ & & & & & \\
\hline 77 & 2 & 239.89890 & & & $\mathrm{x}$ & & & & & $\mathrm{x}$ & \\
\hline 78 & 5 & Disaccharide & & & & $\mathrm{x}$ & & & & & \\
\hline 79 & 15 & Cyclic ADP-ribose & & $\mathrm{x}$ & $\mathrm{x}$ & $\mathrm{x}$ & $\mathrm{x}$ & & & & \\
\hline 80 & 7 & Dipeptide $^{c}$ or Lysopine or Rideopine & & & & & $\mathrm{x}$ & & & & \\
\hline 81 & 2 & Dipeptide $^{\mathrm{k}}$ & & & & & $\mathrm{x}$ & & & & \\
\hline 82 & 9 & 2',3'-cGMP or 3',5'-cGMP & & & & & & & $\mathrm{x}$ & & \\
\hline
\end{tabular}




\begin{tabular}{|c|c|c|c|c|c|c|c|c|c|c|}
\hline 83 & 1 & Isoguanine or Oxyadenine & & & & & & & & $\mathrm{x}$ \\
\hline 84 & 1 & Dehydrohexose & $\mathrm{x}$ & & $\mathrm{x}$ & & & & & \\
\hline 85 & 8 & Di/tripeptide ${ }^{\mathrm{h}}$ & & & $\mathrm{x}$ & $\mathrm{x}$ & $\mathrm{x}$ & $\mathrm{x}$ & & \\
\hline 86 & 5 & Deoxyhexose & & $\mathrm{x}$ & $\mathrm{x}$ & $\mathrm{x}$ & $\mathrm{x}$ & & & \\
\hline 87 & 11 & Dipeptide $^{i}$ & & & $\mathrm{x}$ & $\mathrm{x}$ & $\mathrm{x}$ & $\mathrm{x}$ & & \\
\hline 88 & 2 & Dipeptide $^{\mathrm{d}}$ & & & & & $\mathrm{x}$ & & & \\
\hline 89 & 8 & Dipeptide $^{1}$ & & & $\mathrm{x}$ & $\mathrm{x}$ & $\mathrm{x}$ & $\mathrm{x}$ & & \\
\hline 90 & 7 & Di/tripeptide ${ }^{\mathrm{h}}$ & & & & & $\mathrm{x}$ & & & \\
\hline 91 & 2 & Deoxyguanosine & & & $\mathrm{x}$ & & & & & \\
\hline 92 & 8 & Dipeptide $^{1}$ & & & $\mathrm{x}$ & $\mathrm{x}$ & $\mathrm{x}$ & & & \\
\hline 93 & 2 & Pro-Tyr or Tyr-Pro & & & & & $\mathrm{x}$ & & & \\
\hline 94 & 2 & 549.11226 & & & & & $\mathrm{x}$ & & & \\
\hline 95 & 15 & 238.10523 & & $\mathrm{x}$ & $\mathrm{x}$ & $\mathrm{x}$ & $\mathrm{x}$ & & & \\
\hline 96 & 2 & Di/tripeptide ${ }^{\mathrm{h}}$ & & & & & $\mathrm{x}$ & & & \\
\hline 97 & 5 & Deoxyhexosethreonine & & $\mathrm{x}$ & $\mathrm{x}$ & $\mathrm{x}$ & $\mathrm{x}$ & & & \\
\hline 98 & 2 & 620.11598 & & & $\mathrm{x}$ & $\mathrm{x}$ & $\mathrm{x}$ & $\mathrm{x}$ & & $\mathrm{x}$ \\
\hline 99 & 1 & Tripeptide $^{\mathrm{m}}$ & & & & & & $\mathrm{x}$ & $\mathrm{x}$ & \\
\hline 100 & 2 & Di/tripeptide ${ }^{\mathrm{h}}$ & & & $\mathrm{x}$ & $\mathrm{x}$ & $\mathrm{x}$ & $\mathrm{x}$ & & \\
\hline 101 & 9 & 2',3'-cUMP or 3',5'-cUMP & & & & & & $\mathrm{x}$ & & \\
\hline 102 & 9 & 500.02419 & & & & & & $\mathrm{x}$ & & \\
\hline 103 & 5 & 5-methoxycarbonylmethyluridine & & $\mathrm{x}$ & $\mathrm{x}$ & $\mathrm{x}$ & $\mathrm{x}$ & & $\mathrm{x}$ & \\
\hline 104 & 5 & Pro-Leu & & & $\mathrm{x}$ & $\mathrm{x}$ & $\mathrm{x}$ & & & \\
\hline 105 & 1 & Tripeptide/peptide $^{\mathrm{n}}$ & & & & & & $\mathrm{x}$ & $\mathrm{x}$ & \\
\hline 106 & 2 & 218.10373 & & $\mathrm{x}$ & $\mathrm{x}$ & $\mathrm{x}$ & $\mathrm{x}$ & & $\mathrm{x}$ & \\
\hline 107 & 3 & Dipeptide $^{o}$ & & & $\mathrm{x}$ & & & & & \\
\hline 108 & 4 & Ala-Phe & & & $\mathrm{x}$ & & & & & \\
\hline 109 & 2 & 288.09615 & & $\mathrm{x}$ & $\mathrm{x}$ & & & & & \\
\hline 110 & 2 & Tripeptide $^{\mathrm{m}}$ & & & & & $\mathrm{x}$ & & & \\
\hline 111 & 2 & 427.56868 & & & & & $\mathrm{x}$ & & & \\
\hline 112 & 6 & 550.09609 & & & & & $\mathrm{x}$ & & & \\
\hline 113 & 8 & Gly-Phe & & & $\mathrm{x}$ & $\mathrm{x}$ & $\mathrm{x}$ & & & \\
\hline
\end{tabular}




\begin{tabular}{|c|c|c|c|c|c|c|c|c|c|c|}
\hline 114 & 1 & Phomone $\mathrm{A}$ or $\mathrm{B}$ or Blumeoside $\mathrm{C}$ & & & & & & & & $\mathrm{x}$ \\
\hline 115 & 2 & Dinucleotide & & $\mathrm{x}$ & $\mathrm{x}$ & $\mathrm{x}$ & $\mathrm{x}$ & & & \\
\hline 116 & 1 & 283.11683 & $\mathrm{x}$ & & & & & $\mathrm{x}$ & & \\
\hline 117 & 1 & Peptide $^{\mathrm{p}}$ & $\mathrm{x}$ & & & & & $\mathrm{x}$ & & \\
\hline 118 & 2 & Thr-Trp or Trp-Thr & & & $\mathrm{x}$ & $\mathrm{x}$ & $\mathrm{x}$ & $\mathrm{x}$ & & \\
\hline 119 & 2 & 531.13646 & & $\mathrm{x}$ & $\mathrm{x}$ & $\mathrm{x}$ & $\mathrm{x}$ & & & \\
\hline 120 & 5 & 397.13389 & & & $\mathrm{x}$ & $\mathrm{x}$ & $\mathrm{x}$ & & & \\
\hline 121 & 2 & 279.12977 & & $\mathrm{x}$ & $\mathrm{x}$ & $\mathrm{x}$ & $\mathrm{x}$ & & & \\
\hline 122 & 2 & Tripeptide/peptide $^{\mathrm{n}}$ & & & & & $\mathrm{x}$ & & & \\
\hline 123 & 3 & Ser-Phe or Phe-Ser & & & $\mathrm{x}$ & & & & & \\
\hline 124 & 1 & 428.06072 & & & & & $\mathrm{x}$ & & & $\mathrm{x}$ \\
\hline 125 & 12 & 231.14696 & & & $\mathrm{x}$ & & & & & \\
\hline 126 & 2 & Peptide $^{q}$ & & $\mathrm{x}$ & $\mathrm{x}$ & $\mathrm{x}$ & $\mathrm{x}$ & & & \\
\hline 127 & 4 & Di/tripeptide ${ }^{r}$ & & & $\mathrm{x}$ & & & & & \\
\hline 128 & 2 & Tyr-Tyr & & & $\mathrm{x}$ & & & & & \\
\hline 129 & 1 & Tripeptide $^{\mathrm{m}}$ & & & & & & $\mathrm{x}$ & $\mathrm{x}$ & \\
\hline 130 & 2 & Peptide type compound $^{\mathrm{s}}$ & & & $\mathrm{x}$ & & & & & \\
\hline 131 & 4 & Di/tripeptide ${ }^{t}$ & & & $\mathrm{x}$ & & & & & \\
\hline 132 & 6 & Gly-Phe/Phe-Gly methyl ester & & & & & $\mathrm{x}$ & & & \\
\hline 133 & 9 & Dipeptide $^{\mathrm{e}}$ & & & & & & $\mathrm{x}$ & & \\
\hline 134 & 1 & Dipeptide $^{j}$ & & & & & & $\mathrm{x}$ & & \\
\hline 135 & 9 & Deoxythymidine & & & & & & $\mathrm{x}$ & & \\
\hline 136 & 7 & Dipeptide $^{\mathrm{u}}$ & & & & & $\mathrm{x}$ & & & \\
\hline 137 & 1 & 571.14232 & & & & & & & & $\mathrm{x}$ \\
\hline 138 & 7 & 626.10191 & & & & & $\mathrm{x}$ & & & \\
\hline 139 & 1 & Ala-Trp & & & & & $\mathrm{x}$ & $\mathrm{x}$ & & \\
\hline 140 & 2 & Acetylvaline & & & & & $\mathrm{x}$ & & & \\
\hline 141 & 2 & 457.57568 & & $\mathrm{x}$ & $\mathrm{x}$ & $\mathrm{x}$ & $\mathrm{x}$ & $\mathrm{x}$ & & \\
\hline 142 & 7 & Dipeptide $^{j}$ & & & & & $\mathrm{x}$ & & & \\
\hline 143 & 1 & $\alpha$-Asp-Phe & & & & & & $\mathrm{x}$ & & \\
\hline 144 & 3 & Leu-Leu & & & $\mathrm{x}$ & & & & & \\
\hline
\end{tabular}




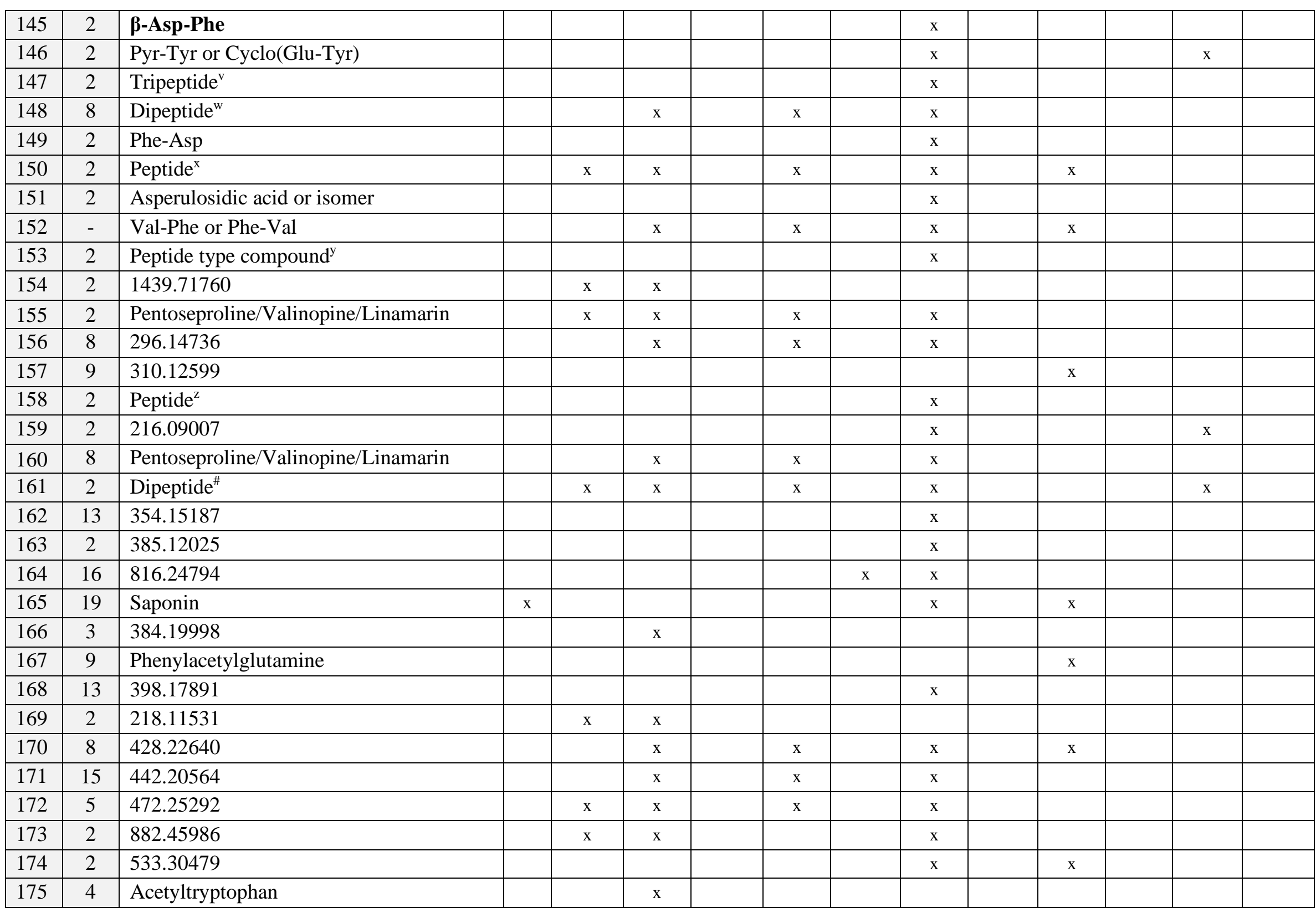




\begin{tabular}{|c|c|c|c|c|c|c|c|c|c|c|c|c|c|c|}
\hline 176 & 2 & Tripeptide/peptide ${ }^{\S}$ & & $\mathrm{x}$ & $\mathrm{x}$ & & & & $\mathrm{x}$ & & & & & \\
\hline 177 & 17 & Ramulosin derivative & & & $\mathrm{x}$ & & & & $\mathrm{x}$ & & & & & \\
\hline & & $\Sigma$ metabolites & 21 & 22 & 93 & 4 & 64 & 2 & 89 & 2 & 37 & 4 & 8 & 16 \\
\hline
\end{tabular}

$\mathbf{a}=$ Is detected by the $[2 \mathrm{M}+\mathrm{H}]^{+}$ion due to the $\mathrm{m} / \mathrm{z}$ range used.; b=Dipeptide containing Leu or Ile and Lys; $\mathbf{c}=$ Dipeptide containing Leu or Ile and Ser or Thr and

Val; $\mathbf{d}=$ Dipeptide containing Leu or Ile and Asn or Gln and Val; $\mathbf{e = D i p e p t i d e ~ c o n t a i n i n g ~ L e u ~ o r ~ I l e ~ a n d ~ A s p ~ o r ~ G l u ~ a n d ~ V a l ; ~} \mathbf{f = D i p e p t i d e ~ c o n t a i n i n g ~ L e u ~ o r ~ I l e ~ a n d ~}$ Arg; $\mathbf{g = T r i p e p t i d e ~ c o n t a i n i n g ~ A l a , ~ A s p ~ a n d ~ G l n ~ o r ~ G l n , ~ G l u ~ a n d ~ G l y ~ o r ~ A l a , ~ A s n ~ a n d ~ G l u ~ o r ~ a ~ t e t r a p e p t i d e ~ c o n t a i n i n g ~ A l a , ~ A l a , ~ A s p ~ a n d ~ G l y ~ o r ~ A l a , ~ G l u ~ G l y ~ a n d ~}$ Gly or the methyl ester of acetylated tripeptide containing Asn, Gly and Ser; h=Dipeptide containing Leu or Ile and Gln; or a tripeptide containing Ala, Gly and Leu or Ile; or Ala, Ala and Val; or the methyl ester of an acetylated dipeptide containing Gly or Ala and Lys; or the ethyl ester of Ala-Ala-Ala or a tripeptide containing Gly, Gly and Val; or an acetylated dipeptide containing Thr and Val; or the methyl ester of a tripeptide containing Gly, Gly and Leu or Ile; or the methyl ester of a dipeptide containing or Asn and Leu or Ile; or Val and Gln; or the methyl ester of a tripeptide containing Ala, Gly and Val; $\mathbf{i}=$ Dipeptide containing Leu or Ile and Thr; $\mathbf{j}=$ Dipeptide containing Leu or Ile and Glu; $\mathbf{k}=$ Dipeptide containing Phe and Thr or the methyl ester of a dipeptide containing Phe and Ser or Ala and Tyr; or the ethyl ester of a dipeptide containing Gly and Tyr; or the phenyl methyl ester of a dipeptide containing Ala and Ser; l=Dipeptide containing Leu or Ile and Gly or Ala and Val; m=Tripeptide containing Asp, Thr and Leu or Ile; Or Glu, Ser and Leu or Ile; or Glu, Thr and Val; or the methyl ester of a tripeptide containing Asp, Thr and Val; or an acetylated tripeptide containing Ser, Thr and Val; n=Tripeptide containing Gly, Glu and Leu or Ile; or Ala, Asp and Leu or Ile; o=Dipeptide containing Leu or Ile and Val; p=Tripeptide-amide containing Pyr, Glu and Pro; q=Tetrapeptide containing Cys, Met, Thr and Thr or Met, Met, Ser and Ser; r=Dipeptide containing Asn and Phe or a tripeptide containing Gly, Gly and Phe; or a dipeptide-amide containing Asp and Phe; or an acetylated dipeptideamide containing Gly and Tyr or the phenyl methyl ester of Gly-Gly-Gly; s=Pyr-Phe or Cyclo(3-OH-Pro-Tyr) or Acetylmethoxy-Trp; $\mathbf{t}=$ Dipeptide containing Gln and Phe or a tripeptide containing Ala, Gly and Phe or the methyl ester of a dipeptide containing Asn and Phe or the methyl ester of a tripeptide containing Gly, Gly and Phe or the phenyl methyl ester of a dipeptide containing Gln and Gly or the phenyl methyl ester of a tripeptide containing Ala, Gly and Gly; u=Dipeptide containing Leu or Ile and Met; v=Tripeptide containing Ala, Glu and Tyr; or Asp, Phe and Thr; or Glu, Phe and Ser or the methyl ester of a tripeptide containing Asp, Phe and Ser; w=Dipeptide containing Leu or Ile and Tyr; x=Tetrapeptide containing Gln, Glu, Glu and Leu or Ile; or a pentapeptide containing Ala, Asp, Asp, Val and Val; or Asp, Pro, Ser, Ser or Leu or Ile; or Ala, Ala, Glu, Glu And Val; or Ala, Ala, Asp, Glu and Leu or Ile; or Ala, Glu, Glu, Gly and Leu or Ile; or Asp, Asp, Gly, Val and Leu or Ile; or Asp, Pro, Thr, Ser, Val; or Glu, Pro, Ser, Ser and Val; or Ala, Glu, Pro, Thr and Thr; y=Dipeptide containing Glu and Phe or Abenquine B1 or Abenquine B2; z=Pentapeptide containing Pro, Pro, Thr, Thr and Leu or Ile; or Glu, Gly, Pro, Leu or Ile and Leu or Ile; or Ala, Asp, Pro, Leu or

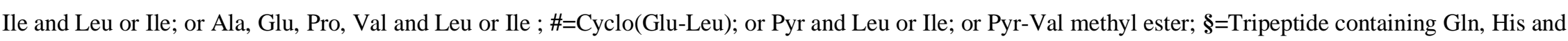
Leu or Ile; or a tetrapeptide containing Ala, Gly, His and Leu or Ile; or Ala, Ala, His and Val; or an acetylalted tripeptide containing Ala, His and Lys; or the methyl ester of a tripeptide containing Pyr, Arg and Pro; or a pentapeptide-amide containing Ala, Gly, Gly, Pro and Pro 
Table 3 The antioxidant activity of authentic standard compounds tested with SCAV and ORAC methods. Activity is indicated with + and inactivity with -. The threshold values chosen were $>3 \% \mathrm{H}_{2} \mathrm{O}_{2}$ inhibition for SCAV and $>500 \mathrm{TE} \mu \mathrm{mol} / \mathrm{L}$ for ORAC. Positive controls used in the tests were sodium pyruvate for SCAV and E-vitamin derivative Trolox for ORAC.

\begin{tabular}{|c|l|c|c|}
\hline $\begin{array}{l}\text { \# in } \\
\text { Table 2 }\end{array}$ & & SCAV & ORAC \\
\hline 9 & Ala-Gln & + & - \\
\hline 52 & tyrosine (Tyr) & + & + \\
\hline 65 & uridine & - & - \\
\hline 67 & Ala-Tyr & - & - \\
\hline 69 & Leu-Ala & - & - \\
\hline 104 & Pro-Leu & + & - \\
\hline 108 & Ala-Phe & - & + \\
\hline 113 & Gly-Phe & + & - \\
\hline 139 & Ala-Trp & - & - \\
\hline 143, & Asp-Phe (tested as Asp-Phe methyl ester) & - & + \\
\hline 145 & & + & \\
\hline 144 & Leu-Leu & & \\
\hline- & tryptophan (Trp) & + & \\
\hline
\end{tabular}

